\title{
Public participatory GIS in community-based disaster risk reduction
}

\author{
Randall B. Kemp \\ Information School, University of Washington, Seattle, Washington, USA, rbkemp@u.washington.edu
}

\begin{abstract}
Natural hazards, such as earthquakes and floods, result in disasters for several reasons. One of the important factors is reducing risk before an incident arises. Such efforts are commonly termed disaster risk reduction (DRR). DRR is the process and engagement of a local community to explore factors of risk and implement methods, practices, and even cultural change, which will reduce the probability that a natural hazard will result in a severe disaster.

In this paper I explore the applicability of public participatory GIS (PPGIS) technologies into DRR efforts. Geographic information systems (GIS) function as an electronic spatial data storage, mapping, and analysis tool compromised of software, hardware, and data inputs. GIS can produce simple maps as well as complicated analysis based on several data sources (or layers). Like standard participatory research methods, PPGIS incorporates end users, research subjects, and researchers into a collaborative environment where GIS are structured under the guidance of both the expert and the novice. One intended result are GIS appropriate to the needs and uses of a given community, with specific attention to the cultural underpinnings of that community.

Introducing PPGIS tools into community-based DRR is not a neutral effort. The information and communication technologies (ICT) embedded in GIS can both aid the DRR efforts as well as impact the community in unintended ways. ICTs may be common in communities engaged in DRR efforts so the introduction of PPGIS may have minimal impact. What are the societal ramifications, however, of PPGIS methods in DRR efforts when ICTs are a relatively new aspect of a given community? What are the communication methods pertinent to PPGIS in the DRR context? How does the ICT literature address PPGIS methods? The paper addresses these and other influences of ICT on societies prone to natural hazards.
\end{abstract}

Keywords: PPGIS, natural hazards, disaster risk reduction, information organization

Acknowledgement: Generous thanks to the anonymous review and helpful feedback from the ICT\&S Doctoral Students' Meeting colleagues.

$\mathrm{T}$ he numbers of people impacted by natural hazards is showing an upward trend. More people are displaced and put into health risk from floods, earthquakes, and drought. Humanitarian actors seek to reduce these risks through development strategies and community-based exercises to assess disaster risk. A key input to these exercises is accurate and extensive information from which communities might make decisions, changes, and plans for moving forward.

\section{Introduction}

This research project explores the information organization practices of a local community in a developing country by deploying a public participatory geographic information system to aid the collection, organization, and use of information with a special focus on geographic information. The goal of the work is to make a contribution to the growing literature around disaster risk reduction and the use of information and communication technologies (ICT) to support community-based risk reduction efforts.

The paper first sets out the research questions and goals of the project along with a brief overview of suggested methods. The next sections then introduce definitions of information, information organization, and information science. These definitions set the 
stage and place the work in a particular discipline. Geographic information is then defined and described, along with geographic information science.

Other key themes are then explored. These themes, in order of presentation, are natural hazards, humanitarian relief organizations, and disaster risk reduction (DRR). A brief survey of additional information organization and geographic information science research is provided.

Before the concluding summary, a detailed example of the possible methods is provided. The paper ends with a concluding summary of the work as well as a short section on potential future research.

The realm of this research project centers on the overlap of information organization patterns of a community-based DRR effort. The type of community in question, briefly, is a small, localized community prone to natural hazards. In this context I seek to address the following research questions.

- How does the community classify its information once it is collected? That is, what are the steps the community takes to organize, label, or otherwise assign significance to the information?

- What is the resultant organization and classification scheme based on the community-based steps of collecting and organizing?

- How does geographic information factor into classification steps and scheme? How pervasive across the organizing scheme are geographic concepts?

- What affordances and limitations do ICTs either natively existent or introduced during the research (such as public participatory geographic information systems (PPGIS), see below) contribute to the classification?

If indeed information is power and wellorganized information aids the decision making process then exploring how communities prone to negative impacts from natural hazards may highlight where local capacity for information gathering and organization can positively reduce risk to disasters. Conversely, the research may highlight missing information and give evidence to those agencies, governments, and people with the power to generate or provide information to local communities.

Utilizing ICTs in the research project, as a means to aid collection and organization particularly of geographic information, may be a powerful tool to draw out information patterns and organization schemes. ICTs, on the other hand, may prove to be a significant hindrance in the collection and organization of information. The goal of the project, then, is not to impose ICTs on the participants but to explore the value of such tools for a given community.

A primary goal of the research is to empower a local community to better assess its natural hazard proclivities and thereby move towards solutions for reducing that risk. The particular structures of information organization and ICTs are scaffolding upon which the community may achieve these results. The research project will contribute to the ongoing conversations in the humanitarian sector regarding beneficiary information needs and the use of technological tools in development.

In order to address the suggested research questions from above, I aim to explore how a small, local community in a developing region might be supported by their use of PPGIS in the DRR efforts with a special focus on the organization of geographic information.

I define a small, local community as one that is bounded by some geographical markers such as a watershed and no more than a population of 5,000 persons. The community will be in a developing country, preferably in a Spanish-speaking region (due to my own rudimentary knowledge of the language). Locating possible communities will come through networking among current contacts in humanitarian relief and development organizations currently enacting DRR projects. I will then seek to work with a variety of people from the community in a small team comprised of local leaders as well as those whose voices are not often heard within that community.

After identifying a community willing to partner in the project, I will devise exercises using GIS pertinent to the region and culture. I expect that this will include both low- and hi- 
tech ICTs such as drawing maps on paper as well as walking around with global positioning system (GPS) devices. These exercises with the community will have as their goal the elucidation of the types of information the community collects in its DRR efforts, the sources of information, how the information is organized, and how the information is then incorporated into decision-making. One exercise might be a set of "what" questions to draw out what kinds of information is collected: what do you need to know about topography? for instance.

Assessing the types of information could then flow into an exercise of gathering specific instances of information into GIS application. If the gathered information on first blush did not have a spatial component, another set of questions could be asked to explore how a piece of information might actually be tied to a specific place within or affecting the community. At first the collection of information might be straightforward and logically be placed in the spatial database. After the gathering of more data, however, it may be necessary to build together a more structured and organized spatial repository.

Another exercise could entail the making of a map on a poster-sized piece of paper of where the community perceives their boundaries to be. As a follow-on exercise, the team could then plot, using a GPS, the boundaries by walking the perimeter of the boundary. A comparison could then be made of the similarities between the original map and the plotted boundaries to see how the team organizes what is in and what is outside of their community.

The significant power of GIS is their ability to layer and analyze data over a defined space. Consequently, another step in the PPGIS efforts potentially undertaken in this project is to explore with the team, once data has been collected, the interactions of various data points with one another. I expect this phase of the participatory research will require some collaborative hardware and software in order for the whole team to look at and ask questions of the data using the computer tools. The group could be shown some simple analytical possibilities then solicit questions from the team that they want to ask of the data. I would then ask questions of the team regarding the organization of information.

A step I would take at the start of the research with the local community is to ask them individually how they organized information for their DRR efforts. I would ask them to identify specific categories of information they collect along with definitions for those categories. I would also ask them to describe how the various categories connect with each other as like-dislike, in a hierarchy, etc. Towards the end of the participatory exercises, then, we as a team would seek to draw out the categories of information as illuminated in the GIS and compare them to the original categories provided by the individual team members.

Since I am exploring how ICTs, specifically GIS, act as an affordance or impediment to information gathering, organization, and use, I will engage the team in reflective exercises about the perceived aid or detriment of GIS in the DRR effort. I will ask for examples and stories from the team to corroborate their analysis.

The above questions and exercises remain possibilities at this juncture of the research. Participatory methods are both planned and spontaneous depending on how the group moves the exploration along. I am not attempting to prescribe exercises that must be completed but rather options to be used in case circumstances warrant.

In the following sections I set out the background literature, definitions of terms, and description of the fields in question.

\subsection{Information}

In this section definitions of information are provided as a means to frame the research around further issues of information organization. Additionally, a picture of information science is given as the home discipline for the research.

\subsubsection{Definitions of Information}

First off, there is no one accepted definition of information, even within information science (IS) (Buckland, 1991). Prior to the rise of IS as a named field, MacKay (1953, p. 62) defined information as "that which adds to a 
representation of what is known or believed or alleged to be the case." Buckland (1991, p. 356) made famous in the IS community the "information-as-thing" notation, under the belief that "we are unable to say confidently of anything that is could not be information." The "thing" could be a scream of terror or an antelope, for instance. The critical point in his argument centers on an object or event being informative, and this can be left to a matter of individual judgment. Writing later, Buckland (1999) uses an appropriate metaphor when he writes, "I am increasingly impressed by the complexity of the 'landscape' of Information Science," and includes, as an example under "many specialized genres," geographical information systems.

Taking a cue from Edwin Parker, Bates (2006) defines information as the patterns of organization of matter and energy. Further, Bates claims that these patterns are not inherently meaningful, but can be assigned meaning by people. From patterns to value, Losee (1997) wrote, "Information is produced by all processes and it is the values of characteristics in the processes' output that are information."

Just because information is recorded recorded information is what some consider the domain of IS (see more below) - does not indeed qualify it as information. This claim, made by Floridi $(2004,2005)$, posits that misinformation is not really information at all because it is not meaningful or well formed. But requiring information to be useful information is not a stance Losee (1997, p. 257 ) is willing to accept because it "excludes the information carried by a subatomic particle which is not sensed by a cognitive process."

Important for the discussion at hand is the notion of embedded information. Such information is left behind by animals (and humans) in the environment. Bates (2006) uses the example of a spider building its web. Elsewhere, Bates (2005) articulates her notion of information and its importance for IS: "I have long felt that to succeed in the process of developing a broadly applicable, encompassing understanding of information for our field, we must begin at the physical and biological levels and move up to the cultural, social, cognitive and aesthetic."
For the purposes of this paper, I define information as the substance of an idea or thing which represents that idea or thing; it communicates something to the person; and it need not be recorded to be information because information is inherent rather than realized through some contingency of its packaging. Related to the project at hand, then, this definition can encompass the local knowledge of community members as well as the technical geographic information gleaned from computer devices. The value of the local knowledge is not in its collection, packaging, or recording, but it inherently is information. The act of recording it on a map does not make it information.

\subsubsection{Information Organization}

Information organization (IO) makes explicit the relationships among information objects, primarily by "bringing all the same information together" (Svenonius, 2001, p. 10). A simple example is the grouping a music lover employs to categorize her record collection by genres such as classical, jazz, blues, and gospel. Some relationship then exists for all the records in the classical category. $I O$ is the task of grouping, arranging, and representing information to draw connections and relationships among information so that conclusions and new knowledge emerge from these connections (Dahlberg, 2006, p. 12). These connections highlight similarities as well as differences, as the rudimentary example of music grouping shows. Additionally, $I O$ intends to engender a common communication platform built around the connections such that the explicit linkages facilitate understanding of ideas among a variety of people (Albrechtsen and Jacob, 1998). IO (also known as Knowledge Representation or Knowledge Organization) is primarily a subfield within IS but is not an exclusive member of that discipline, because the activities and frameworks of $\mathrm{IO}$ cut across other disciplines, including geographic information science (GISci).

The domain of 10 arises from certain questions articulated by both researchers and practitioners. Some of these questions include, what characteristics of object (or concept) $A$ are shared with object $B$ ? In the 
making of lists of any kind, what are the important skeletal frameworks upon which humans organize? What do we do with a new idea that has no place in an existing organization structure? Can we devise a scheme so hospitable, that all concepts and objects have a place?

Intuitively, we all group and classify. People of all professions and cultures build piles on their desks, categorize, and otherwise inherently classify things based on organizational structures, unconscious leanings, and cultural practices (Bowker and Star, 1999). Going one step further, the accepted categories we all take for granted are not quite so predictable and uniform as we might think (Lakoff, 1987). In fact, one-sizefits-all classification schemes tend to fail (Albrechtsen and Jacob, 1998). IO exists because of these factors: humans categorize, we think we know what categories signify, and we pursue universal categorization schemes even when they do not satisfy.

$1 \mathrm{O}$, in short, is grouping like information objects together. It is the drawing of intentional links within and across these groupings. There may or may not be a purpose or goal in the organizing. The groupings do, however, provide an opportunity to then tell a story about the information objects and how they are grouped, which can be important in the decision-making process. The organization of information by the community members in this project, noted in the early phases of the suggested activities detailed below will reveal itself as the members discuss their perceptions of their geography. The groupings they make, taken on their own and in conjunction with information organized by GIS, may result in new observations for both the community members and interpretation of GIS data. That is, the linkages articulated by the community members may be a more accurate representation of reality than the linkages arrived at by computer algorithms.

\subsubsection{Information Science}

Just as the right definition of information is elusive, there is no consensus on what IS is (Zins, 2006). Adding yet another dimension to terminology (e.g., what are the differences, if any, between data, information, and knowledge), Zins argues that "information science" should be "knowledge science." According to Houser (1988) the term "information science" gained popularity in the 1960s Schrader (1984), and has most often been defined as the "study of the gathering, organizing, storing, retrieving, and dissemination of information" (Bates, 1999, p. 1044). In a classic definition of the field, Borko (1968, p. 4) articulates the essence of IS research: "investigates the properties, and behavior of information, the use and transmission of information, and the processing of information for optimal storage and retrieval."

There is debate over whether IS concerns itself only with recorded information. Bates (1999) states that the domain of IS is primarily (but not solely) recorded information. "The special focus of LIS is on documented knowledge produced by human beings in some kind of documents of potential use to other human being" (Hjørland, 2003, p. 93). On the other hand, "Information is more than recorded words and languages; it is images, music, light, any entity that interacts as largely as in concert with the universe or as minutely as subatomic particles" (Norton, 2000, p. 5)

One important aspect of IS tied to the human side is that of communication. Made famous by Shannon \& Weaver is the idea of sending and receiving messages. IS has taken communication (an equally vague term as is information (cf. Saracevic, 1992) to heart.

The definition of IS I employ for this paper is that it is the study of the collection, organization, and re-use of information. For the project at hand, then, each of those characteristics is at play.

\subsection{Geographic Information}

Now that information, information organization, and information science have been defined and explored, the concepts of geographic information and geographic information science are articulated. The research uses geographic information and the associated ICTs familiar in that realm to further frame and narrows the research space. 
When humanitarian actors, such as nongovernmental organizations (NGOs), local governments, and the United Nations (UN), respond to an emergency such as a disaster or a more protracted complex emergency, they require information about the context and situation of specific locations in order to best assess and respond with aid. Ideally these multiple actors (and even multiple units within a given organization) share information in order to best alleviate suffering and quicken the arrival of stability and humane conditions. Much of this information, quite naturally, has spatial attributes. Spatial attributes include a simple location, such as a given village in Pakistan, or a specific section of coastline within Mississippi or Indonesia.

\subsubsection{Geographic Information Science Definitions and Background}

Geographic information (Gl) has been defined as "information about features and phenomena located in the vicinity of the surface of the Earth" (Goodchild et al., 1999, p. 732), including human activities that occur on it (Goodchild, 2000). Gl is then a subset of spatial information, where "spatial," in contrast to "geo," is not tied to the earth, e.g., the human body, an automobile, or the universe (Goodchild, 2001). Gl is minimally a list of two variables: a location in space-time and attributes associated with that space (Goodchild et al., 1999). An example from an IS perspective supports the same definition: "GI is defined by the use of spatial and temporal referencing to characterize information" (Raper et al., 2002, p. 39).

Geographic information science emerged as a scientific field in the late 1980s (Mark et al., 1999) and it contains the components of data collection, data modeling, structuring, and analysis of GI (Goodchild, 1992). "GISci ... is concerned with geographic concepts, the primitive elements used to describe, analyze, model, reason about, and make decisions on phenomena distributed on the surface of the earth" (Wright et al., 1997, p. 357, emphasis in original).

GISci emerged from the study of geographic information systems (GIS) (used in the plural), which function as an electronic spatial data storage, mapping, and analysis tool. GIS appeared in the 1960s (Goodchild, 2003) and then later became an object of study as researchers sought to develop a science around the tool. The types of questions GISci asks include: How can Gl be represented? How can Gl be quantified, and what metrics of $\mathrm{Gl}$ measure its volume (Duckham et al., 2003, p. 1)? How is Gl best collected and organized? How can relationships among Gl be signified?

\subsection{Natural Hazards}

The next three sections define key concepts in the research space. These concepts sit primarily in the humanitarian relief and development sector and are natural hazards, humanitarian relief organizations, and disaster risk reduction. All three are critical to the research, the research questions, and the community-based nature of the research.

Natural processes such as earthquakes, tsunamis, and hurricanes comprise a subset of the causes for landscape change. These environments, one might assume from the sheer number of news reports about devastating disasters, appear to be facing an upswing in catastrophic events impacting both natural landscapes and human populations.

The evidence for such an increase in the intensity of disasters and the consequences on human life and property is mixed. Those killed by disasters between 1917 and 1932 surpassed 3 million in six different years, largely due to pandemics (cf. EM-DAT: The OFDA/CRED International Disaster Database. Université Catholique de Louvain, Brussels, Belgium, available at http://www.emdat.be). In contrast, no year since 1960 has recorded more than 600,000 deaths. When comparing the mean number of deaths over ten-year spans in the last 40 years, the death count is lower in the most recent decade than in the first or second decade. The mean number of deaths due to disasters for 1966-1975 was 198,864 ; 1976-1985 was 103,751 ; 19861995 was 46,068; and 1996-2005 was 88,896 .

The figures reveal a different pattern when the number of people affected - the homeless, jobless, sick - by disasters is counted. The trend is decidedly increasing, 
even if the counts for individual years rise and fall. The mean number of persons affected per year from 1996 to 2005 was 240,250,791. Such a staggering number only obscures the myriad factors influencing its growth such as an increasing global population, higherdensity populations, and increased populations living in environmentally unstable systems, among others. What the number does suggest, however, is the need for a concerted effort to alleviate suffering from disasters to so many people.

The estimated monetary damages sustained during given years show a decidedly upward trend. Between 1996 and 2005 the mean estimated monetary cost for disasters runs to $\$ U S 65.6 \mathrm{bn}$, which does not include the estimated cost from the Kobé, Japan, earthquake in 1995 of \$US 121bn.

\subsection{Humanitarian Relief Organizations}

Into this context rises the humanitarian relief field with all its policies, organizations, guiding documents, and goodwill. Humanitarian relief organizations hold as a significant goal the alleviation of suffering on the part of disaster survivors and others affected by complex emergencies. These organizations supply local people with food, shelter, and health care by sending personnel and working with pre-planned organizations already on the ground in vulnerable areas.

Jurisdiction questions concerning land, data, and reputation are significant in the humanitarian relief context. Multiple actors participate in humanitarian relief operations. During the tsunami relief efforts governments from around the world pledged monetary support as well as personnel transports into Indonesia and Sri Lanka. In addition, the UN, the European Union, and other multi-lateral organizations provided services of various kinds. On top of this, literally hundreds of NGOs, some newly formed after the disaster, inundated villages. Where relief operations became chaotic due to the sheer numbers of NGOs, some NGOs attempted to organize the many players while others found people under-served and refocused energies there (IFRC, 2005). All this to say, jurisdiction questions in such a, potentially, contentious environment beg for, at a minimum, procedures designed to increase the efficiency of coordination, which may involve data management capabilities and policies on standards (not only for data coordination but for other practical aspects of relief efforts such as food and shelter). Second, beyond coordination, issues of legal and de facto jurisdiction in times of disaster operations belong in the hands of international humanitarian law experts.

Humanitarian action (HA) is the work of assisting communities facing short- and longterm crises, including disasters, complex emergencies like a protracted civil war, economic deprivation, and infringements on basic human rights. Humanitarians seek to support what Sen (1999) champions: people have a "freedom to" in the economic, social, and political spheres of their lives. HA typically includes work in the major phases of the disaster cycle: mitigation (actions designed to reduce the impact of future disasters), preparation, response, and recovery (Alexander, 2002). A more familiar term than HA is "humanitarian relief and development" (HRD), which demarcates too precisely between something called "relief" and something called "development," when in reality these are stages on a continuum (Lindenberg and Bryant, 2001).

$\mathrm{HA}$ efforts include the delivery of aid such as food, shelter, and medical care. HA also includes community involvement with distressed and vulnerable groups before disaster strikes with education, shared planning, and evaluation. HA includes a robust health assessment of a region and intentional infrastructure expansion to improve the health of local populations so they are better prepared to weather storms, droughts, and illness. Holistic HA focuses on supporting locally empowered communities towards greater resiliency. Another name for this last concept is disaster risk reduction.

\subsection{Disaster Risk Reduction}

The combination of humanitarian actors in a setting of natural hazards is the process of disaster risk reduction (DRR). DRR is a framework where practitioners and community members, ideally, work together to identify vulnerabilities to natural hazards and change 
systems, policies, and habits in order to avoid or limit the destructive impacts of a hazard (HPN, 2007; ISDR, 2007).

DRR efforts seek to assess local conditions, gather data, and then share out that data with others in order to paint a clearer picture of natural hazard realities as well as to educate local communities on the potential risks (ISDR, 2007, p. 14). There are challenges, however, to data collection coverage, methodologies, and reporting information systems (UNDP, 2004; DFID, 2005).

Climate change research has increased as a perceived need in order to provide more detailed data regarding natural hazard risk (O'Brien et al., 2006; van Aalst, 2006). Alongside climate change research, investigations into the concept and practice of resilience has also increased (Manyena, 2006; Bosher et al., 2007). Part of the equation into assessing hazard risk is the use of community-based disaster preparedness (see more below on community-based methods) assisted by information technology tools (Troy et al., 2007). International aid and development organizations are investing resources in the education of communities about risk to natural hazards (Wamsler, 2006) and addressing their own challenges with integrating the DRR framework into their own efforts (Schipper and Pelling, 2006).

\section{Existing Research}

At the start of this paper, topics such as information, information science, and geographic information were defined and explored through a literature review. The following two sections expand on that effort by further extrapolating particularly pertinent concepts from information organization and geographic information science research. These concepts will help inform the methodology and analysis of findings.

\subsection{Information Organization Research}

The 10 literature speaks of naïve classifications as a useful concept. Naïve (or folk) classification systems are "created by people who have no particular interest or training in classificatory design and implementation" (Beghtol, 2004, p. 19). Professional classification systems, on the other hand, are typically predicated on the world of pre-existing knowledge while naïve classifications systems concern themselves with a limited set of knowledge tied to a particular context and purpose in which they arise. Additionally, naïve systems are typically more shallow in their hierarchy and number of examples than are professional systems (Beghtol, 2004, p. 21).

Context, as in the journalist's who, what, where, when, why questions, is a significant construct in IO. The context greatly impacts the "what" and "why" of an organizing scheme. "One of the determinants of purpose for a classification system is generally the context from which it arose and in which it is to be used" (Beghtol, 2004, p. 20). Devising an appropriate classificatory structure is supported by a collaborative effort of a shared discourse among information intermediaries (however defined, e.g., librarians) and the end users of such a structure (Albrechtsen and Jacob, 1998; Mai, 2004a). "Given classifications tend to fit more or less with the pre-understandings of given (sub)cultures" (Hjørland, 2002, p. 454). While each user community is unique, within a given community heterogeneity also exists (Olson and Schlegl, 2001). In summary, context provides foundational building blocks upon which a useful organization scheme can be constructed.

Domain-analysis, as used in $\mathrm{IO}$, is one framework which intentionally focuses on context as the driving factor of an organization scheme. "The context of any classification influences the use and understanding of the classification to such a degree that the classification cannot be understood separate from its context" (Mai, 2002, p. 472), which is a postmodern view looking at specific domains rather than at the universe of knowledge (Mai, 2004a). Domain-analysis ties the "construction of classification schemes to the discourse and activities of the users of the documents" (Mai, 2004a, p. 45). The language used by the domain in question is also a vital aspect of any classification work, work that is "inherently political and valueladen" (Mai, 2004a, p. 46). The domainanalysis approach is also critical in the 
indexing (establishing the subject matter of an object and assigning terms from, typically, a controlled vocabulary, of documents). What terms are assigned by the indexer will help or hinder the users' access of that information. If the indexer takes into consideration the domain, the communication, essentially, between the indexer and the user will be clearer (Mai, 2004b).

The purpose and goal of an organizing scheme belong in this discussion of context and are highlighted as a particular aspect of context because the end goal of a scheme dramatically affects the design and implementation of the scheme. It is also true that classificatory schemes are political tools because their creation, at least within the context of an organized group of people, carries an "agenda of discipline and control over organization members' actions" (Suchman, 1994, p. 178). If categorizing people within an organization impose control on a person's responsibility and freedom, imposing bibliographic control over documents, as another example, also implies power over those information objects (Wilson, 1968, p. 6). Both Yates (1989) and the telling case studies in McPhee (1989) explore control: one the organizational, the other nature itself. The purpose of an organizing structure need not contain the potentially insidious goal of power. Instead, certain values, views, and biases subjectively facilitate or hinder effectiveness of that structure (Olson, 1998, 2001; Olson and Schlegl, 2001; Svenonius, 2001; Hjørland, 2002, 2003).

Bowker (1998, p. 255) adroitly highlights the "relationship between the use of the classification as an information storage and retrieval mechanism and its use to encode multiple political and ethical agendas." A scheme cannot, however, classify every possible bit of relevant information but must make practical trade-offs (1998, p. 261) because the system is developed within a context of organizational practice (1998, p. 264). Additionally, the inflexibility of such schemes reinforces the existing organization of information because changes to the scheme impact the usefulness of previously organized information (1998, p. 268), even though schemes might represent one period in time (with the knowledge known and recorded at that time) while the world has changed (Bowker, 1998, p. 271). So, the context is not only that of the intellectual content of a given scheme but also the people, place, and time (1998, p. 273). Optimistically, the political nature (rigidity) of a scheme allows the scientific community to communicate, publish, research, and otherwise conducts its work due in, at least a small, part to the scheme at hand (1998, p. 284).

In the family of constructs subsumed under the heading of context, the notion of a universal classification scheme can now be discussed in light of context and purpose of a scheme. Since information organizing schemes, to be effective, are contextualized and created with a purpose, building a scheme with universal applicability can be successful only if success is defined as attending to the lowest common denominator and completely satisfying only a portion of users (Mai, 2002, p. 477). The primary emphasis of contextualization, then, is on local classification schemes tied to specific needs and goals of a defined community.

The users of a classification scheme are considered an important contributor to framing the context and purpose of the scheme. They are, therefore, integrated into the design of the scheme. Although the sentiment that "it is important to involve the eventual users of the [HA] information in the design and development of the collection process" (Granger, 2000, p. 21) is present in HA discussions, participation of beneficiaries in the processes of HA more often than not, when they touch on information issues, center on extraction of information from beneficiaries over and above sharing information with beneficiaries or incorporating them into the information collection decisions. One reason for this is that they are not viewed as users of information but providers only (IFRC, 2005). See Cooke and Kothari (2001); Brown et al. (2003); Eversole (2003) for critical perspectives - both positive and cautionary on participatory research in development. HA can learn from the 10 construct of valuing local context by including users in the design and implementation of information organization schemes so that the scheme will 
more appropriately attend to the needs of beneficiaries.

\subsection{GISci Research}

Context is also an important construct in GISci, such that pragmatism and experience play critical roles in the geographer's design of categories. A geographer is unable to meet the needs of all other geographers, so must instead focus on what works in the given context of categorization (Gray, 1997). Writing about how to evaluate GI, Raper et al. (2002, p. 43) remind the reader that "the relevance of information is task- and context-dependent and requires a model of information needs."

Domains, tightly related to context, also appear in GISci writings as a significant construct. In attempting to classify vegetation patterns in areas on the earth where it was unclear what vegetation was actually present, Ahlqvist et al. (2003) utilized automatic reclassification of the vague areas based on specific domain knowledge. GIS analysis depends on domain and is appropriately carried out under the context of the theoretical and pragmatic characteristics of a given discipline in a local context (Burrough and Frank, 1995).

The purpose and goal of collecting and analyzing $\mathrm{Gl}$ also fits into the present discussion of contextualization. The $\mathrm{GI}$ in question, collected within a particular context, carries with it implicit and explicit value based substantially on what the recipient of that information considers being the requirements and purpose of the effort at hand (Worboys, 2003, p. 33). Transportation flow researchers, for example, will focus on collecting traffic patterns, volume of cars, and time-todestination information. They may not be so concerned with roadside vegetation unless tree and shrub height might be a factor in traffic speed. Such information collection would depend on the purpose of the research effort.

A human-centered approach in GISci, as opposed to one focused on a tool or on information itself voids of context, is another contextual construct. Such an approach reduces the fragmentation of people and activities from location and calls for an integration of a place- and people-based perspective rather than focusing solely on the place (Miller, 2003). The human-centered approach holistically examines the entire ecology of a location as humans interact in that context. To cite an obvious example, it takes into account the human use of a public park rather than isolating the vegetation, soil, and precipitation characteristics of the park while ignoring the human interaction in and with the park.

The human aspect is vital as well in the study of networks within social groupings, and "the analysis of space and place has become an increasingly pivotal component of social science research in the past two decades" (Goodchild et al., 2000, p. 139). Part of this increase is in the study of multi-faceted networks of actors, both in business and social aspects more broadly. These transnational interconnections are ideal grounds for exploring space-time research issues. See Barabási (2002) for a complete examination of how networks are linked.

Stephenson (2005) favors coordination without a top-down approach. He instead suggests social networks are more effective in garnering trust, which leads to improved sharing. "It is important to realise that it is not control, but trust, that can substitute for certainty [of information]" (Benini, 1997, p. 351). Trust is imperative to knowledge transfer (Powell, 2003; Sida and Szpak, 2004; Chua et al., 2007).

Naïve geography takes into consideration what people believe to be true about Gl even if scientific explanations differ (Goodchild, 2001). The term is not intended to disparage intellectual capability but to signify instinctive or spontaneous reflection of how people think and reason about GI (Egenhofer and Mark, 1995). The focus is then on the commonsense reasoning about geographic space with the intention of producing GIS which incorporate this reasoning in order for the computer tools to be used by nonprofessionals with minimal training.

The technology can also take too much prominence in GISci. At times, there can be a focus on hardware over data, with sophisticated databases and analysis available without the corresponding robust data to go with it (Goodchild, 1992). 
Warschauer (2004) raises similar issues in his helpful book on how ICT may help or actually exacerbate the digital divide. Even with quality data, however, another concern is the overoptimistic use of technology. To counter an inordinate focus on the technology and to raise ethical considerations of technology use, GISci researchers need to admit when optimism is unfounded and leverage research showing how this over-optimistic use of technology impacts equity and representation (Goodchild et al., 1999, p. 740). Issues of equity and representation include access to information and broad representation of people, ideas, and concepts not in the main stream.

\section{Proposed Methodology}

Before outlining proposed research activities, some background of working with research subjects and participants who are refugees is provided. The research activities suggested below do not include working with refugees, but some of the characteristics, warnings, and ethical considerations are apropos.

After the brief discussion of refugees, public participatory methods in general are described as a likely framework for exploring the research questions above. Public participatory GIS is then outlined.

\subsection{Information Gathering on Environmental Refugees}

The first tactic is to gather more information about and from the refugees themselves. Crisp (2003) notes that aid agencies supposed to alleviate the suffering of refugees do not possess a full understanding of these same refugees. Consequently, research on refugees must begin with a thorough effort to learn more about them.

Some of the challenges to collecting information from and about environmental refugees include their wish to remain anonymous, possible threats to informants from host governments, beneficiaries of humanitarian aid telling researchers what they want to hear instead of accurate answers, access to an adequate sampling frame, validity of information gathered in often extreme conditions, re-traumatizing survivors, and the safety of researchers (Jayatilaka and Muggah, 2004; Uehling, 2004).

Research begins by devising ways to hear directly from the powerless refugees themselves, including women and children (Crisp, 2003). General and one-off surveys will not suffice as adequate information gathering tools. Advocating for "hanging out" with refugees, Rodgers (2004) is critical of the shallow information gleaned from surveys and instead argues that investing more time listening to refugees in their context will be the best research tactic. Such face-to-face interaction is vital according to Introna (2002) rather than mediating access to refugees through numbers, statistics, or impersonal surveys. In a well-documented report covering the information needs of disaster survivors, several authors provide multiple cases of the 2004 tsunami survivors and their lack of information (IFRC, 2005).

\subsection{Participatory Action Research}

Participatory research sets its focus on incorporating multiple stakeholders in the formulation and execution of research in more than a simple survey instrument. Participants, in this social science research effort, have a voice in the research efforts, as they are one of the primary intended beneficiaries of the research itself. The participants aid the researcher in generating the questions, the methods, and even in analysis. There is not one set participatory method but participatory methods fall on a spectrum of possibilities. If the intent of the research is to simply gather information, participatory methods may add a greater than necessary overhead to the project. If, on the other hand, it is desired that participants also take ownership of some outcome or share in decision-making, then participatory methods may be vital (Freudenberger, 1999, p. 5)

Participatory action methods are used with the intention of increasing the democratic, shared nature of research and results (Brown et al., 2003). Rather than a top-down imposition of research methods and findings, the more bottom-up approach of participatory research seeks to level the playing field, share power, and highlight marginalized voices 
(Walker et al., 2007). The presence of participatory methods in a research project, however, does not guarantee shared power. Some have postulated that participation is just another form of tyranny (Cooke and Kothari, 2001), that participatory methods maintain the power structure of those intervening over those less developed (McKinnon, 2007), that including the marginalized can actually hamper their autonomy (O'Reilly, 2004), that real participation is often elusive (Eversole, 2003), and that participatory research is full of paradoxes (Howcroft and Wilson, 2003). It is also posited that participatory action research is supported by strong scientific evidence (Ottosson, 2003).

Utilizing a participatory approach to the context of disaster risk reduction, taking the warnings mentioned in the previous paragraph seriously, results in what a recent paper calls participatory disaster risk assessment (PDRA) (Pelling, 2007). The level of participation in this type of research method can vary along a spectrum and can be explored at various stages where community members might be involved: "initiating the assessment; identifying what is at risk; identifying the sources of hazard, vulnerability or capacity; designing assessment methods; collecting data; analyzing data; drawing conclusions for action; acting on results; and reviewing the usefulness of the assessment" (Pelling, 2007, p. 379). The community-based risk assessment process is time consuming but is also intended to provide a rich, contextual outcome owned by the participants themselves.

\subsection{Public Participatory GIS}

When incorporating context, domain, and human-centered approaches in GISci, public participatory GIS (PPGIS) stands out as an exemplary construct (Harvey and Chrisman, 1998; Nyerges et al., 2002; Sieber, 2003; Aggett and McColl, 2006; Sieber, 2006). Like participatory research, PPGIS incorporates end users, research subjects, and researchers into a collaborative environment (MacEachren, 2000) where GIS are structured under the guidance of both the expert and the novice. One intended result is GIS appropriate to the needs and uses of a given community, with specific attention to the cultural underpinnings of that community (Poore, 2003) and a raised level of empowerment for the community taking part (Tulloch, 2007).

PPGIS from GISci shares a strong resemblance to domain-analysis from $1 O$ in that both contextualize the users' settings, language, and culture as well as the goals stated by the community in the process of understanding that community. Where PPGIS is unique is in the very purposeful use of GIS technology in the collaborative action research environment. Domain-analysis, on the other hand, does not presuppose a particular technological tool in support of the process. In domain-analysis, the process of devising an organization scheme could produce a low-tech solution such as a file cabinet if that meshed with the culture and context better. So, domain-analysis and PPGIS share similar inputs but the outputs are defined differently.

The PPGIS construct is one logical method for consciously attending to the unique features of a given context. PPGIS methods encourage both the practitioners and those affected by a humanitarian situation to partner together in assessing a situation, gathering information, devising possible solutions, and deciding on a plan together. PPGIS is applicable to HA because the people most affected by the humanitarian need are in the centre of the process in a decision-making role rather than standing on the outside in an observer role.

Another possible GISci tool which can be applied in HA contexts is a multi-user, multimodal GIS (Rauschert et al., 2002). Such a tool set is a combination of inputs from a computer mouse, touch screen, pen device, or track ball alongside a large screen. The large screen and multiple input devices permit several users to work jointly in observing and analyzing GI. Incorporating this technology into PPGIS methods holds promise for HA because the practitioners, both non-experts and expert GIS analysts, and beneficiaries can access and manipulate Gl together, keeping the human side of the context in sight. Of course PPGIS, especially with a tool as described in this paragraph, requires 
infrastructure investment. Other less technology-dependent methods do exist.

\subsection{Example Project}

Now that terms, background information, and the potential tools have been outlined above, a descriptive example of how the many options might be collected into a formal PPGIS project is in order. As mentioned previously, this is not a prescriptive recipe, but rather a descriptive possibility. I focus on the use of GIS in the project.

Activity One - A Paper-Based, MemoryDerived Map of the Local Watershed: In this first step towards leveraging the strengths of GIS, the researcher will gather the community group (described above in the introductory section) and ask each member to individually graphically represent their local watershed. The outcome for each may be a drawing on paper showing boundaries, landmarks, waterways, and the built environment. Others may choose to narrate instead of draw their perception of the watershed. Still others may draw the map using more organic materials such as plant materials to represent the watershed.

As a group, then, we will attempt to combine the various interpretations of the geography into a single representation on a large piece of paper. We will negotiate understandings of the space and boundaries through stories, legal definitions, and informal agreements of property rights. The outcome for Activity One will be a rudimentary map of the watershed based on community input.

Activity Two - Ground-truthing the Community Map: Taking the map in hand, the community group will then walk the watershed to verify the accuracy of the map. We will do so with the aid of a GPS as a means to precisely note the location of landmarks, boundaries, water features, and the built environment (such as homes, roads, dams, planting fields, etc.).

After collecting as many data points with the GPS as possible, the group will then begin the comparison of the original map to the map generated from the ground-truthing exercise. The group will see where correlations and discrepancies exist between the two maps and have opportunity to explore the reasons for both.

The GPS allows the precise notations of location of features, which may differ from memory. The GPS is a fairly unobtrusive device comparable in size to a large mobile phone. Even so, the unit will be explained to the group so everyone understands what it is and what it does.

Activity Three - Collaborative Spatial Decision Making: The formal examination of the outputs from Activity One and Activity Two will take the form of a computer-based exercise with a fully-functional GIS, large computer monitors, and multiple humanoperated input devices. The devices could include a normal mouse, a pen input device for marking/drawing on a computer screen, or even a large touch screen.

The original map will be displayed to the group alongside the map generated from the ground-truthing. The two maps will then be overlaid on each other to visually show to all users where overlaps and discrepancies exist. The original paper-based map will first be transformed into a digital representation.

With the large screens and input devices, the group can then redraw boundaries or highlight locations of other landmarks missed in Activity One or Activity Two. Additionally, layering ground cover, water features, roads, buildings, temperature zones, and locations of natural hazards on both maps can indicate where human activities might need to be altered, the existence of sites susceptible to hazards, and hazard-free sites.

The community can then ask questions of the data using the layers of data. For landslide hazards: slope angles, soil composition, and land cover. For flooding: water runoff, stream locations, and flood plains. And so on for other types of hazards.

\section{Conclusions}

As this research project is a work-inprogress, I cannot report on findings from the field as of yet. I hope to articulate findings from the research activities which provide clear evidence that the use of ICTs in disaster risk reduction efforts are a key contributor to improved information gathering, organization, access, and use. GIS, in their extreme 
application are sophisticated and a challenge to manipulate. I hope to conclude that a moderate implementation of GIS (more than simply making pretty maps but also geographic analysis) in the DRR project gives the community new knowledge upon which they can make decisions about reducing the negative impacts of natural hazards.

\section{Future Research}

Additional questions, if the preliminary ones I am asking now bear fruit, include issues of wide-spread access to geographic information through ICTs, long-term use of ICTs in DRR efforts without an expert present, how formal training of local participants in ICT use might take place so that the participants might then train others, and who are the community members left out of the information sharing dialog.

Further research might also include the use of emerging geographic information technologies not necessarily part of the pantheon of GIS and tools. These might include a GPS-enhanced mobile phone, a location-aware handheld device, open source GIS in a local telecenter, or the dispersal of smart-clusters of miniature devices set to passively gather environmental data then transmit it back to a central source. The environments of those regions most impacted my natural hazards is wide open for exploring and creativity in the gathering and organizing of geographic information. ICTs are one way to leverage the power of information in order to reduce risk and the research questions associated with this effort are many.

\section{References}

Aggett, G. \& McColl, C. (2006). Evaluating decision support systems for PPGIS applications. Cartography and Geographic Information Science, 33(1), 77-92.

Ahlqvist, O. \& Keukelaar, J. \& Oukbir, K. (2003). Rough and fuzzy geographical data integration. International Journal of Geographical Information Science, 17(3), 223-234.

Albrechtsen, H. \& Jacob, E. K. (1998). The dynamics of classification systems as boundary objects for cooperation in the electronic library. Library Trends, 47(2), 293-312.

Alexander, D. (2002). Principles of emergency planning and management. Oxford: Oxford University Press.

Barabási, A.-L. (2002). Linked: The new science of networks. Cambridge, MA: Perseus.

Bates, M. J. (1999). The invisible substrate of information science. Journal of the American Society of Information Science, 50(12), 1043-1050.

Bates, M. J. (2005). Information and knowledge: An evolutionary framework for information science. Information Research, 10(4), paper 239. Retrieved December 05, 2008, from http://InformationR.net/ir/10-4/paper239.html

Bates, M. J. (2006). Fundamental forms of information. Journal of the American Society of Information Science \& Technology, 57(8), 1033-1045.

Beghtol, C. (2004). Naïve classification systems and the global information society. In C. Mcllwaine (Ed.), Proceedings of the Seventh International ISKO Conference, volume 9, London, 2004 (pp. 19-22). Würzburg: Ergon.

Benini, A. A. (1997). Uncertainty and information flows in humanitarian agencies. Disasters, 21(4), 335-353.

Borko, H. (1968). Information science: What is it? American Documentation, 19(1), 3-5.

Bosher, L. \& Carrillo, P. \& Dainty, A. \& Glass, J. \& Price, A. (2007). Realising a resilient and sustainable built environment: Towards a strategic agenda for the United Kingdom. Disasters 31(3), 236-255.

Bowker, G. C. (1998). The kindness of strangers: Kinds and politics in classification systems. Library Trends, 47(2), 255292.

Bowker, G. C. \& S. L. Star (1999). Sorting things out: Classification and its consequences. Cambridge: MA: MIT Press.

Brown, L. D. \& Bammer, G. \& Batilwala, S. \& Kunreuther, F. (2003). Framing practice-research engagement for democratizing knowledge. Action Research 1(1), 81-102.

Buckland, M. (1991). Information as thing. Journal of the American Society for Information Science, 42(5), 351-360.

Buckland, M. (1999). The landscape of information science: The American Society for Information Science at 62. Journal of the American Society for Information Science, 50(11), 970-974.

Burrough, P. A. \& Frank, A. U. (1995). Concepts and paradigms in spatial information: Are current geographical information systems truly generic? International Journal of Geographical Information Systems, 9(2), 101-116.

Chua, A. Y. K. \& Kaynak, S. \& Foo, S. S. B. (2007). An analysis of the delayed response to Hurricane Katrina through the lens of knowledge management. Journal of the American Society of Information Science \& Technology, 58(3), 391 403. 
Cooke, B. \& Kothari, U. (Eds.) (2001). Participation: The new tyranny? London: Zed Books.

Crisp, J. (2003, September). Why do we know so little about refugees? How can we learn more? Forced Migration Review, 18,55 .

Dahlberg, I. (2006). Knowledge organization: A new science? Knowledge Organization 33(1), 11-19.

DFID Department for International Development (2005). Disaster risk reduction: A development concern. Retrieved December 5, 2008, from http://www.dfid.gov.uk/Pubs/files/disaster-risk-reduction.pdf

Duckham, M. \& Goodchild, M. F. \& Worboys, M. F. (Eds.) (2003). Foundations of geographic information science. London: Taylor \& Francis.

Egenhofer, M. J. \& Freksa, C. \& Miller, H. J. (Eds.) (2004). Geographic Information Science, Lecture Notes in Computer Science; 3234, Adelphi, MD. Berlin: Springer.

Egenhofer, M. J. \& Mark, D. M. (1995). Naïve geography. In A. U. Frank \& W. Kuhn (Eds.), Spatial information theory: A theoretical basis for GIS : COSIT '95, Lecture notes in computer science; Austria (pp. 1-15). Berlin: Springer.

Eversole, R. (2003). Managing the pitfalls of participatory development: Some insight from Australia. World Development, 31(5), 781-795.

Floridi, L. (2004). Outline of a theory of strongly semantic information. Minds and Machines, 14, 197-221.

Floridi, L. (2005, March). Is semantic information meaningful data? Philosophy and Phenomenological Research, 70(2), 351-370.

Freudenberger, K. (1999). Rapid Rural Response Appraisal \& Participatory Rural Appraisal (RRA/PRA). CRS publication. Retrieved June 2, 2008, from http://crs.org/publications/pdf/Gen1199 e.pdf

Goodchild, M. F. (1992). Geographical information science. International Journal of Geographical Information Systems, 6(1), 31-45.

Goodchild, M. F. (2000). Communicating geographic information in a digital age. Annals of the Association of American Geographers, 90(2), 344-355.

Goodchild, M. F. (2001). A geographer looks at spatial information theory. In D. R. Montello (Ed.), COSIT, Lecture notes in computer science; 2205, Morro Bay, CA (pp. 1-13). Berlin: Springer.

Goodchild, M. F. (2003). Geographic information science and systems for environmental management. Annual Review of Environmental Resources, 28, 493-519.

Goodchild, M. F. \& Anselin, L. \& Appelbaum, R. P. \& Harthorn, B. H. (2000). Toward spatially integrated social science. International Regional Science Review, 23(2), 139-159.

Goodchild, M. F. \& Egenhofer, M. J. \& Kemp, K. K. \& Mark, D. M. \& Sheppard, E. (1999). Introduction to the Varenius project. International Journal of Geographical Information Science, 13(8), 731-745.

Granger, K. (2000). An information infrastructure for disaster management in Pacific island countries. Australian Journal of Emergency Management, 15(1), 20-32.

Gray, M. V. (1997). Classification as in impediment to the reliable and valid use of spatial information: A disaggregate approach. In S. C. Hirtle \& A. U. Frank (Eds.), COSIT 97: Spatial information theory: A theoretical basis for GIS, Lecture Notes in Computer Science; 1329, Laurel Highlands, PA, (pp. 137-149). Berlin: Springer.

Harvey, F. \& Chrisman, N. (1998). Boundary objects and the social construction of GIS technology. Environment and Planning, A 30, 1683-1694.

Hjørland, B. (2002). The methodology of constructing classification schemes: A discussion of the state-of-the-art. In M. J. López-Huertas (Ed.), Proceedings of the Seventh International ISKO Conference, volume 8, Granada, Spain (pp. 450-456). Würzburg: Ergon.

Hjørland, B. (2003). Fundamentals of knowledge organization. Knowledge Organization, 30(2), 87-111.

Houser, L. (1988). A conceptual analysis of information science. Library and Information Science, 10, 3-34.

Howcroft, D. \& Wilson, M. (2003). Paradoxes of participatory practices: The Janus role of the systems developer. Information and Organization, 13, 1-24.

HPN (2007, June). Disaster risk reduction. Humanitarian Exchange, 38, 1-32.

IFRC (2005). World disasters report 2005: Focus on information in disasters. Bloomfield: Kumarian Press.

Introna, L. D. (2002). The (im)possibility of ethics in the information age. Information and Organization, 12, 71-84.

ISDR (2007). Words into action: A guide for implementing the Hyogo framework. Retrieved December 5, 2008, from http://www.unisdr.org/eng/about isdr/isdr-publications/02-words-into-action/words-into-action.pdf

Jayatilaka, D. \& Muggah, R. (2004, May). Where there is no information: IDP vulnerability assessments in Sri Lanka's borderlands. Forced Migration Review, 20, 39-41.

Lakoff, G. (1987). Women, fire, and dangerous things: What categories reveal about the mind. Chicago: University of Chicago Press.

Lindenberg, M. \& Bryant, C. (2001). Going global: Transforming relief and development NGOs. Bloomfield: Kumarian Press.

López-Huertas, M. J. (Ed.) (2002). Proceedings of the Seventh International ISKO Conference, Volume 8, Granada, Spain. Würzburg: Ergon. 
Losee, R. M. (1997). A discipline independent definition of information. Journal of the American Society of Information Science, 48(3), 254-269.

MacEachren, A. M. (2000). Cartography and GIS: Facilitating collaboration. Progress in Human Geography, 24(3), 445-456. MacKay, D. M. (1953). Quantal aspects of scientific information. IEEE Transactions on Information Theory, 1(1), 60-80.

Mai, J.-E. (2002). Is classification theory possible? Rethinking classification research. In , M. J. López-Huertas (Ed.), Proceedings of the Seventh International ISKO Conference, Volume 8, Granada, Spain (pp. 472-478). Würzburg: Ergon.

Mai, J.-E. (2004a). Classification in context: Relativity, reality, and representation. Knowledge Organization, 31(1), 39-48.

Mai, J.-E. (2004b). The role of documents, domains and decisions in indexing. In I. C. Mcllwaine (Ed.), Proceedings of the Seventh International ISKO Conference, Volume 9, London (pp. 207-213). Würzburg: Ergon.

Manyena, S. B. (2006). The concept of resilience revisited. Disasters, 30(4), 433-450.

Mark, D. M. \& Freksa, C. \& Hirtle, S. C. \& Lloyd, R. \& Tversky, B. (1999). Cognitive models of geographical space. International Journal of Geographical Information Science, 13(8), 747-774.

Mcllwaine, I. C. (Ed.) (2004). Proceedings of the Seventh International ISKO Conference, Volume 9, London. Würzburg: Ergon.

McKinnon, K. (2007). Postdevelopment, professionalism, and the politics of participation. Annals of the Association of American Geographers, 97(4), 772-785.

McPhee, J. A. (1989). The control of nature. New York: Farrar, Straus and Giroux.

Miller, H. J. (2003). What about people in geographic information science. Computers, Environment and Urban Systems, 27, 447-453.

Montello, D. R. (Ed.) (2001). COSIT, Lecture notes in computer science; 2205, Morro Bay, CA. Berlin: Springer.

Norton, M. J. (2000). Introductory concepts in information science. Medford, NJ: ASIS.

Nyerges, T. \& Jankowski, P. \& Drew, C. (2002). Data-gathering strategies for social-behavioural research about participatory geographical information system use. International Journal of Geographical Information Science ,16(1), 1-22.

O'Brien, G. \& O'Keefe, P. \& Rose, J. \& Wisner, B. (2006). Climate change and disaster management. Disasters, 30(1), 6480.

Olson, H. A. (1998). Mapping beyond Dewey's boundaries: constructing classificatory space for marginalized knowledge domains. Library Trends, 47(2), 233-254.

Olson, H. A. (2001). The power to name: Representation in library catalogs. Signs, 26(3), 639-668.

Olson, H. A. \& Schlegl, R. (2001). Standardization, objectivity, and user focus: A meta-analysis of subject access critiques. Cataloging \& Classification Quarterly, 32(2), 61-80.

O'Reilly, K. (2004). Developing contradictions: Women's participation as a site of struggle wihtin an Indian NGO. Professional Geographer, 56(2), 174-184.

Ottosson, S. (2003). Participation action research: A key to improved knowledge of management. Technovation, $23,87-94$.

Pelling, M. (2007). Learning from others: The scope and challenges for participatory disaster risk assessment. Disasters, 31(4), 373-385.

Poore, B. S. (2003). The open black box: The role of the end-user in GIS integration. Canadian Geographer, 47(1), 62-74.

Powell, M. (2003). Information management for development organizations (2. ed.). Oxford: Oxfam GB.

Raper, J. \& Dykes, J. \& Wood, J. \& Mountain, D. \& Krause, A. \& Rhind, D. (2002). A framework for evaluating geographical information. Journal of Information Science, 28(1), 39-50.

Rauschert, I. \& Agrawal, P. \& Sharma, R. \& Fuhrmann, S. \& Brewer, I. \& MacEachren, A. (2002). Designing a humancentered, multimodal GIS interface to support emergency management. In GIS '02: Proceedings of the 10th ACM international symposium on Advances in geographic information systems (pp. 119-124). New York: ACM Press.

Rodgers, G. (2004, September). 'Hanging out' with forced migrants: Methodological and ethical challenges. Forced Migration Review, 21, 48-49.

Saracevic, T. (1992). Information science: Origin, evolution and relations. In P. Vakkari (Ed.), Conceptions of library and information science: Historical, empirical, and theoretical perspectives (pp. 5-27). London: Taylor Graham.

Schipper, L. \& Pelling, M. (2006). Disaster risk, climate change and international development: Scope for, and challenges to, integration. Disasters, 30(1), 19-38.

Schrader, A. M. (1984). In search of a name: Information science and its conceptual antecedents. Library and Information Science Research, 6, 227-271.

Sen, A. (1999). Development as freedom. New York: Anchor.

Sida, L. \& Szpak, C. (2004, Aug). An evaluation of Humanitarian Information Centers: Including case studies of HICs for Iraq, Afghanistan, and Liberia. Retrieved December 5, 2008, from http://www.reliefweb.int/rw/lib.nst/db900sid/LHON67BCX3/\$file/Evaluation HIC USAID Aug 2004.pdf?openelement

Sieber, R. E. (2003). Public participation geographic information systems across borders. Canadian Geographer, 47(1), 5061. 
Sieber, R. E. (2006). Public participation geographic information systems: A literature review and framework. Annals of the Association of American Geographers, 96(3), 491-507.

Stephenson, Jr., M. (2005). Making humanitarian relief networks more effective: Operational coordination, trust and sense making. Disasters, 29(4), 337-350.

Suchman, L. (1994). Do categories have politics? The language/action perspective reconsidered. Computer Supported Cooperative Work, 2, 177-190.

Svenonius, E. (2001). The intellectual foundation of information organization. Cambridge: MIT Press.

Troy, D. A. \& Carson, A. \& Vanderbeek, J. \& Hutton, A. (2007). Enhancing community-based disaster preparedness with informatino technology. Disasters, 32(1), 149-165.

Tulloch, D. L. (2007, February). Many, many maps: Empowerment and online participatory mapping. First Monday, 12(2). Retrieved December 5, 2008, from http://firstmonday.org/htbin/cgiwrap/bin/ojs/index.php/fm/article/view/1620

Uehling, G. (2004, May). How can we obtain the information we need about refugees? Forced Migration Review, 20, 48.

UNDP (2004). Reducing disaster risk: A challenge for development. Retrieved December 5, 2008, from http://www.undp.org/cpr/whats new/rdr english.pdf

Vakkari, P. (Ed.) (1992). Conceptions of library and information science: Historical, empirical, and theoretical perspectives. London: Taylor Graham.

van Aalst, M. K. (2006). The impacts of climate change on the risk of natural disasters. Disasters, 30(1), 5-18.

Walker, D. \& Jones, III, J. P. \& Roberts, S. M. \& Fröhling, O. R. (2007). When participation meets empowerment: The WWF and the politics of invitation in the Chimalapas, Mexico. Annals of the Association of American Geographers, 97(2), 423-444.

Wamsler, C. (2006). Mainstreaming risk reduction in urban planning and housing: A challenge for international aid organisations. Disasters, 30(2), 151-177.

Warschauer, M. (2004). Technology and social inclusion: Rethinking the digital divide. Cambridge: MIT Press.

Wilson, P. (1968). Two kinds of power: An essay on bibliographical control. Berkeley: University of California Press.

Worboys, M. F. (2003). Communicating geographic information in context. In M. Duckham \& M. F. Goodchild \& M. F. Worboys (Eds.), Foundations of geographic information science (pp. 33-45). London: Taylor \& Francis.

Wright, D. J. \& Goodchild, M. F. \& Proctor, J. D. (1997). GIS: Tool or science? Annals of the Association of American Geographers, 87(2), 346-362.

Yates, J. (1989). Control through communication: The rise of system in American management. Baltimore: The Johns Hopkins University Press.

Zins, C. (2006). Redefining information science: From "information science" to "knowledge science". Journal of Documentation, 62(4), 447-461.

\section{About the Author}

Randall B. Kemp

is $\mathrm{PhD}$ candidate at the Information School at the University of Washington (Seattle, Washington, USA). 